\title{
Shear Tensile and Flexural Performance of Sandwich Composite with Hexagonal Cell Wood Core Variation
}

\author{
Mohd Yuhazri Yaakob ${ }^{1 *}$, Mohd Amirhafizan Husin ${ }^{2}$, Rui Jie Tan ${ }^{3}$, Teng Teng Tan ${ }^{4}$, Kamarul Amir \\ Mohamed $^{5}$, Mohd Syahrin Amri Mohd Noh ${ }^{6}$, Hasoloan Haery Ian Pieter \\ ${ }^{1}$ Faculty of Mechanical and Manufacturing Engineering Technology, Universiti Teknikal Malaysia Melaka, \\ Malaysia,yuhazri@utem.edu.my \\ ${ }^{2}$ Faculty of Manufacturing Engineering, Universiti Teknikal Malaysia Melaka, Malaysia. \\ amirhafizan@gmail.com \\ ${ }^{3}$ Faculty of Mechanical and Manufacturing Engineering Technology, Universiti Teknikal Malaysia Melaka, \\ Malaysia, rextan1996@gmail.com \\ ${ }^{4}$ Faculty of Manufacturing Engineering, Universiti Teknikal Malaysia Melaka, Malaysia. tanjennise@ yahoo.com \\ ${ }^{5}$ Faculty of Mechanical and Manufacturing Engineering Technology, Universiti Teknikal Malaysia Melaka, \\ Malaysia, kamarulamir @utem.edu.my \\ ${ }^{6}$ Faculty of Electrical and Electronic Engineering Technology, Universiti Teknikal Malaysia Melaka, Malaysia, \\ syahrin@utem.edu.my, \\ ${ }^{7}$ PT. Suar Utama Produktifitas, Jakarta Barat, 11420, Indonesia \\ ian_pieter@yahoo.com.sg
}

\begin{abstract}
Current industry demands product with better sustainability and efficiency in terms of weight. This particular demand can be met with introduction of lightweight materials with renewable sources. This article presents a study of sandwich composite with different honeycomb wood core variants and suggests a direction for future development. Six types of sandwich composites, made with rubber wood (RW), pine wood (PW), balsa wood (BW), honeycomb rubber wood (HRW), honeycomb pine wood (HPW), and honeycomb balsa wood (HBW) implemented with hexagonal cells together with glass fibre reinforced polymer skins are studied. Shear tensile and flexural performance of sandwich composites are tested according to ASTM standards. The results reveal that HRW core sandwich composite exhibits good flexural strength amongst the sandwich composite tested while having a proper weight reduction of about $513.92 \mathrm{~kg} / \mathrm{m}^{3}$ compared to solid wood cores. It was also found that, the implementation of hexagonal cells in the wood cores increases the shear tensile performance of the sandwich composites. The results provided may facilitate future applications improvement as well as sustainability development.
\end{abstract}

Key words : balsa wood, honeycomb, pine wood, properties, rubber wood.

\section{INTRODUCTION}

Sandwich structures are lightweight composites that offer high specific flexural strength and stiffness, excellent damping and thermal insulation applied in the automotive, aerospace, and marine and energy industries [1]. In order to meet the needs of industries on the demand for sustainable development and light weight applications, sandwich structures with honeycomb wood cores are one of the suitable candidates for the task. Labans [2] studied the flexural behaviour of sandwich panels with cellular wood, plywood stiffener and thermoplastic composite core, which revealed that the sandwich alternative of solid plywood offers up to $42 \%$ increase in specific stiffness while maintaining sufficient strength. The selected wood variation, which is made of rubber wood, pine wood and balsa, plays a role in sustainability. Particularly rubber wood as rubber wood is widely available in the South East of Asia. Blagodatsky [3] argued that rubber plantations are expanding widely in South East Asia, indicating that Malaysia contributes 8 per cent of world production.

Structure of composite different from laminate and offers excellent stiffness to weight ratio are sandwich panels which is fabricated from two strong and stiff faces separated by a low density core as mentioned by Vitale [4]. The sandwich core increases the flexural stiffness of the sandwich panel with increased moment of inertia under bending. Typical core used in sandwich panels are PVC foams, balsa wood and honeycomb core with the more prominent one in research being honeycomb core. Honeycomb cores demonstrates good compressive strengths which are affected by wall thickness and the core height as mentioned by Sun [5].

Past research has shown a tendency to use natural green materials as a honeycomb core for sandwich composites. 
Riccio [6] studied the impact behaviour of the honeycomb fibre flax core, which involves the manufacture of the honeycomb core of flax fibre and thermoplastic. Lakreb [7] investigated the compressive performance of multilayer sandwich composites made of wood veneer and cork agglomerate cores. Zaini [8] highlighted the rice husk reinforced polymer honeycomb core for sandwich composites in the review, while Walsh [9] investigated the impact performance and energy absorption of the expanded cork core-carbon fibre sandwich composite. In the case of conventional wood-based sandwich-structured composites, an experimental study of the impact behaviour of the sandwich structure made of plywood core and fibre-reinforced composite skin is conducted by Susainathan [1] with emphasis on the fibre-reinforced composite skin type and plywood core type. From the aforementioned studies, it can be seen that while numerous studies have been conducted on the natural material core of honeycombs in sandwich structures as well as conventional wood-based sandwich composites, no attempt has been made to convert the honeycomb structure into wood-based cores.

The objective of the present work paper is therefore to investigate the effects of core variation based on wood, together with the honeycomb structure applied to the shear tension and flexural of the sandwich structure composites. The long term implications of this study will help to address sustainable development and light weight design in material engineering fitting to the demand of the industry.

\section{MATERIALS AND METHODS}

\subsection{Fabrication}

The material used for the face sheet of all sandwich structures (see Figure 1) in this study was a two-layer, $0^{\circ}-90^{\circ}$ woven E-glass reinforced epoxy resin. The core materials used include solid RW, PW and BW as well as wood variants machined with a CNC router for the formation of honeycomb wood of up to six types of sandwich composites. Figure 2 shows the fabrication of hexagonal cell wood core with CNC gantry router with Model pro II MDX-540 from Roland. Figure 3 illustrated the size of the hexagonal core used. The hand lay-up technique was used for the manufacture of the face sheets followed by a vacuum bagging technique for the consolidation of the wood core on the face sheet. The fabricated sandwich structures are then trimmed to the desired geometry for testing on the basis of the required standards.

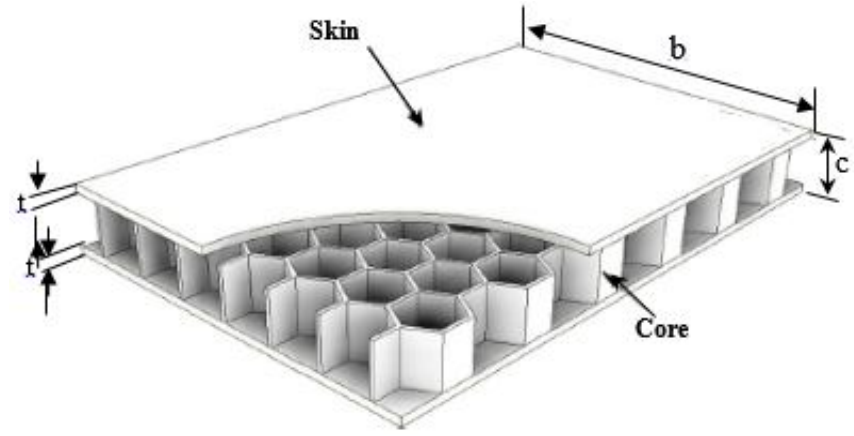

Figure 1: Sandwich panel (Vitale et al. 2017).

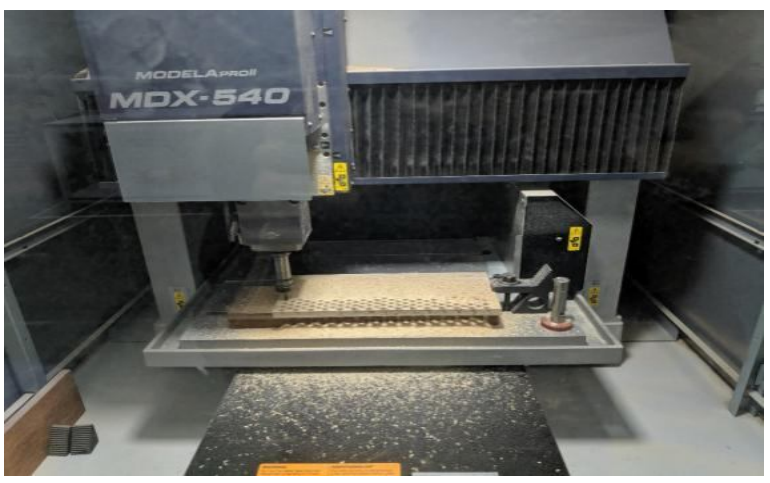

Figure 2: Fabrication of hexagonal cell wood core with CNC gantry router MDX-540
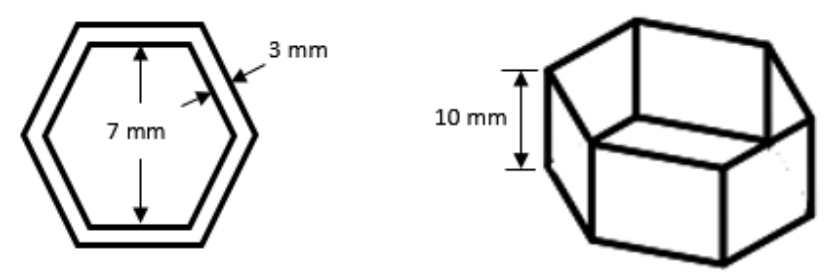

Figure 3: Schematic of cell geometry in wood core used

\subsection{Three-Point Flexural Test}

The ASTM C393 specification standard was used as a reference for a three-point flexural test. The test was performed on the Instron 5969 Universal Testing Machine. The specimens were tested in a 3-point loading configuration with a support span of $150 \mathrm{~mm}$ in length. Samples trimmed according to the specifications in standard dimensions of 200 $\mathrm{mm}$ in length and $75 \mathrm{~mm}$ in width. Five specimens of each composite sandwich variant were tested to determine the result.

\subsection{Shear Testing}

Shear testing of the sandwich structure was carried out in accordance with ASTM C273, where the sandwich structure was trimmed into a $120 \mathrm{~mm}$ long and $50 \mathrm{~mm}$ wide geometry as the sandwich thickness was $12 \mathrm{~mm}$. The specimens are then attached to the specific fixture loaded onto the Universal Testing Machine (Instron 5969) for shear testing. For each sandwich composite variant manufactured, five samples were tested. Modulus and yield stress were used to calculate the test results. 


\section{RESULTS AND DISCUSSION}

\subsection{Flexural Performance}

According to Caglayan [10], the flexural performance of sandwich composites is explained by two key concepts, the strength of the face and the shear strength of the core. This is obtained through a 3-point flexural test and is estimated from the load deflection curves. The results obtained from all five samples for each type of sandwich composite are averaged. Stress obtained was used to calculate flexural strength and specific stiffness. The average flexural strength and specific stiffness data are shown in Table 1.

From the Table 1 and Figure 5, it can be seen that the solid RW sandwich composite has the highest flexural strength compared to the other wood based core composite sandwich. By machining or designating hexagonal cells onto the rubber wood core, the flexural strength of the rubber wood through comparison between the solid RW and HRW cores. HRW core has an average flexural strength of $43.02 \mathrm{MPa}$ which is about $57.64 \%$ lower than the solid RW core flexural strength. In addition, it can be clearly seen that the HRW sample has a heavy face sheet wrinkle on the top face sheet which is in contact with the flexural fixture applying the load to the sample as shown in Figure 4. Face wrinkling is caused by a localized short-wave length buckling of the compression face where the face sheet is compressed by a three-point flexural fixture. After the facial wrinkle failure mode, delamination occurs on the top surface of the samples, where the woven E-glass fibre decoupled from the epoxy matrix as well as the HRW due to wrinkles causes short-wave length buckling.

In addition to face wrinkles and delamination on the top face sheet, cell wall folding can also be observed on samples where the cell wall collapses due to plastic deformation of the sloping cell walls that absorbed energy exceeded its capacity. The cell wall collapsing is observed in the form of intersecting walls cracking and protruding from the sides of the HRW sandwich structure.

The implementation of hexagonal cell onto pine wood core as compared from the solid PW and HPW sandwich composite cause the flexural strength of the HPW to decreases about 36.19 MPa which is $57.97 \%$ of the original solid PW flexural strength. In the case of HBW sandwich composite, the HBW when compared to solid BW core is lower in terms of flexural strength by about $6.33 \mathrm{MPa}$ which is $6.33 \%$ of the strength loss from solid BW core sandwich composite. Comparisons between the hexagonal cell wood based core variations used in sandwich composite shows that the HRW sandwich composite performs the best compared to HPW and HBW. HRW sandwich composite flexural strength value of 43.02 MPa is about $63.94 \%$ higher than HPW sandwich composite and $74.45 \%$ higher than HBW sandwich composite respectively. HPW sandwich composite have a flexural strength that is $13.76 \%$ higher than HBW sandwich composite. Although the hexagonal cell core variant of each wood types tends to have lower flexural strength compared to its solid wood variant, the HRW and HPW sandwich composite have higher flexural strength compared to the conventional SBW sandwich composite used in decking applications. HRW is $148.53 \%$ higher than SBW in terms of flexural strength while HPW is $51.59 \%$ higher than solid BW.

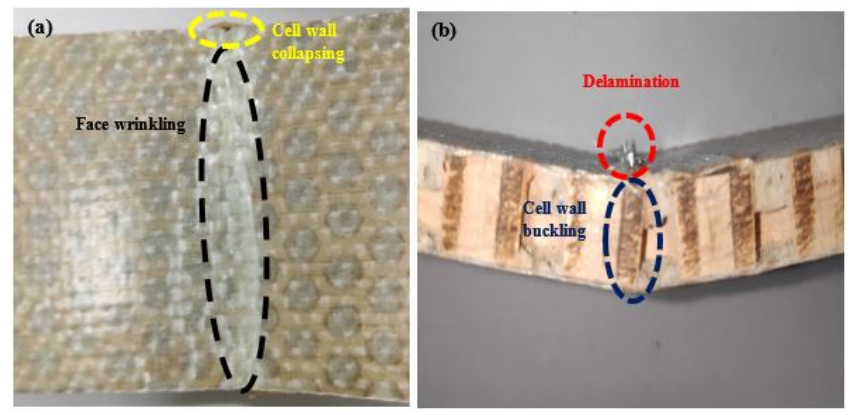

Figure 4: Failure mode present in HRW sandwich structure composite: (a) Top view (b) Side view

Among the solid wood core sandwich composites, the solid $\mathrm{RW}$ is the one with the highest specific stiffness where it is $36.55 \%$ higher than the solid PW and $148.97 \%$ higher than the solid BW. Although lower compared to solid RW and solid PW variant, the specific stiffness of HRW as shown by the data is still higher than the solid BW, HPW and HBW core sandwich composite where the difference in value percentage is $39.82 \%, 43.31 \%$ and $99.07 \%$ higher respectively. The solid RW sandwich composite have the highest flexural strength amongst solid wood core variants and by implementing hexagonal cells in the solid RW core to form HRW core sandwich structure composite the flexural strength and specific stiffness drops marginally.

Although the flexural strength and specific stiffness of HRW sandwich composite is lower than the solid RW and solid PW sandwich composite, the composite still offers great flexural strength which is $43.02 \mathrm{MPa}$ that converts to $438.6 \mathrm{kgf} / \mathrm{cm}^{2}$ as well as proper density reduction from the SRW sandwich composite. Given that the hexagonal cell wood based core variants is inferior to the solid in terms of flexural strength, justification of the hexagonal cell wood based sandwich composite is emphasized whereas the density reduction is deemed to be important and useful in reducing the weight of the composite fabricated as a whole. The HRW and HPW core sandwich composite tested also shows higher specific stiffness and flexural strength compared to solid BW core that is commonly applied in current conventional sandwich structure. This speaks volume about the possibility of both HRW and HPW being the alternatives or replacement to the solid BW sandwich composite. 
Table 1: Density, Flexural Strength and Specific stiffness for each wood base core variant sandwich structure

\begin{tabular}{llll}
\hline $\begin{array}{l}\text { Types of } \\
\text { wood }\end{array}$ & $\begin{array}{l}\text { Density } \\
\left(\mathrm{kg} / \mathrm{m}^{3}\right)\end{array}$ & $\begin{array}{l}\text { Flexural } \\
\text { Strength } \\
(\mathrm{MPa})\end{array}$ & $\begin{array}{l}\text { Specific } \\
\text { Stiffness } \\
(\mathrm{kNm} / \mathrm{kg})\end{array}$ \\
\hline RW & 681.27 & 101.55 & 149.06 \\
PW & 571.90 & 62.43 & 109.16 \\
BW & 289.14 & 17.31 & 59.87 \\
HRW & 513.92 & 43.02 & 83.71 \\
HPW & 449.23 & 26.24 & 58.41 \\
HBW & 261.37 & 10.99 & 42.05 \\
\hline
\end{tabular}

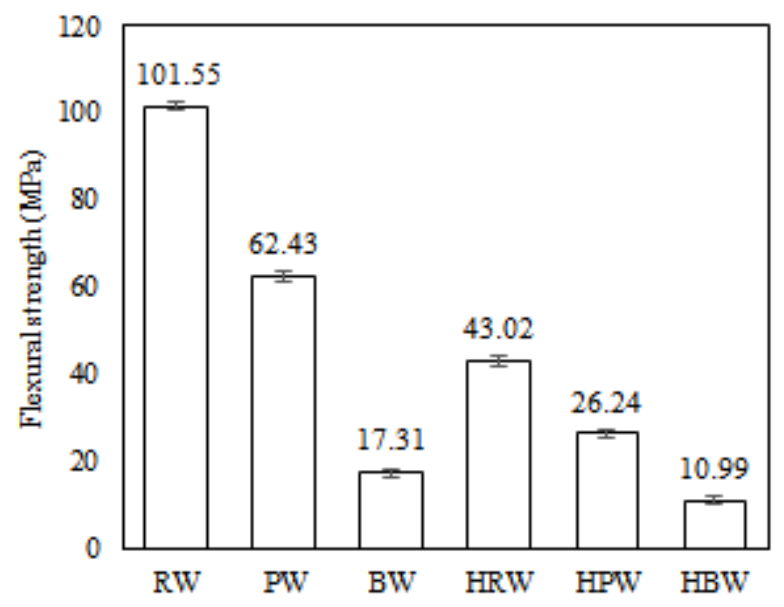

Figure 5: Flexural strength of each wood

\subsection{Shear Tension Performance}

Shear tensile testing under the ASTM C273 standards is used to determine the shear properties of core materials associated with shear distortion of planes parallel to the surfaces. From the results shown in Table 2 and Figure 4, it can be identified that the honeycomb wood core sandwich composite variant has a higher shear strength. This was due to the presence of adhesive fillets between the honeycomb cell wall and the face sheet, which increases the bonding strength of the wood base to the surface. Chen [11] pointed out that smaller adhesive fillets formed between cores and facing means poorer bonding. The presence of honeycomb cells increases the amount of adhesive fillets formed between the core and the surface of the wood, which then increases the bonding strength. The presence of adhesive fillets helps to strengthen the bond between the core and the face by binding the honeycomb cell wall together with the face.

From the Table 2 and Figure 6, it can be observed that the average shear tensile strength of the hexagonal cell wood core variant is higher than its solid wood core counterparts. Where the shear tensile strength of HRW sandwich composite is 1.37 $\%$ higher than solid RW, HPW being $18.09 \%$ higher in shear tensile strength than solid PW and HBW about $75.76 \%$ higher in terms of shear tension strength than solid BW. This increase in the shear fatigue tensile strength shows that by implementing hexagonal cells onto the solid wood cores, the bonding of the glass fibre reinforced polymer (GFRP) face sheets together with the wood based core could be held together more strongly by the epoxy resin acting as the adhesive. Moreover, both adhesive and cohesive failure was observed in the solid PW sandwich composite with adhesive failure failing due to delamination of the GFRP face sheet from the solid PW and cohesive failure failing due to adherent failure of the solid PW. Dawood and Peirick [12] stated that high shear stress may fail the bond line and cause skin-core debonding failure that affects the load bearing capability of the sandwich structure. There is also a case from the samples in which incomplete adhesive failure happened on the tested SPW sample as shown in Figure 6.
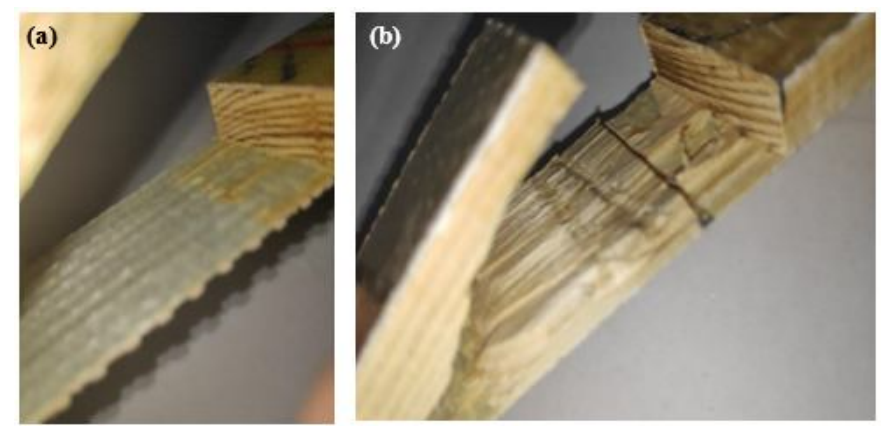

Figure 6: Failure mode of SPW sandwich structure (a) Adhesive failure (b) Cohesive failure

To rank the shear fatigue tension strength of the wood based core sandwich composite from the highest to lowest would be in the order of HPW, solid PW, HRW, solid RW, HBW and finally BW. HPW is the highest in terms of shear fatigue testing in which the value percentage difference is $19.16 \%$ higher than HRW. Although the HRW sandwich composite variant have lower shear fatigue strength than solid PW and HPW, the shear tensile strength of this variant is higher than RW, BW and HBW where it is $187.01 \%$ higher than solid BW and $63.30 \%$ higher than HBW in shear fatigue strength as in Figure 7.

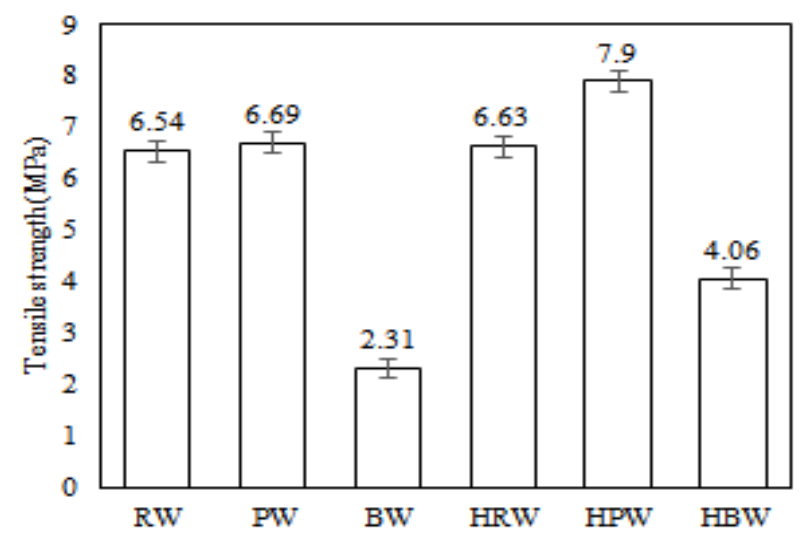

Figure 7: Tensile strength of each wood 
Mohd Yuhazri Yaakob et al., International Journal of Emerging Trends in Engineering Research, 8(1.2), 2020, 195 - 200

Table 2: Average tensile strength and specific tensile strength from shear tension testing of wood based sandwich composite

\begin{tabular}{ccc}
\hline $\begin{array}{l}\text { Types of } \\
\text { wood }\end{array}$ & $\begin{array}{r}\text { Tensile } \\
\text { Strength } \\
(\mathrm{MPa})\end{array}$ & $\begin{array}{c}\text { Specific Tensile } \\
\text { Strength } \\
(\mathrm{kNm} / \mathrm{kg})\end{array}$ \\
\hline RW & 6.54 & 9.59 \\
PW & 6.69 & 11.70 \\
BW & 2.31 & 7.996 \\
HRW & 6.63 & 12.89 \\
HPW & 7.90 & 17.59 \\
HBW & 4.06 & 15.54 \\
\hline
\end{tabular}

In terms of specific tensile strength of the shear fatigue tension, the sample with the highest value is HPW with around $17.59 \mathrm{kNm} / \mathrm{kg}$ followed by HBW with $15.54 \mathrm{kNm} / \mathrm{kg}$ and only by HRW on the third with $12.89 \mathrm{kNm} / \mathrm{kg}$. Difference between specific tensile strength of solid and hexagonal cell wood variants of rubber wood, pine wood and balsa wood are $34.41 \%$ for SRW and HRW, $50.34 \%$ for solid PW and HPW follow up with $62.04 \%$ for solid BW and HBW.

In general, wood based core with hexagonal cells shows better shear fatigue tensile strength compared to solid wood based core sandwich composite. This may be due to the presence of hexagonal cells and adhesion fillet filling up that strengthens the epoxy bonding [13].

\section{CONCLUSION}

The present study was designed to determine the effects of core variation based on wood, together with the honeycomb structure applied to the shear tension and flexural of the sandwich structure composites. From the flexural test and shear tension test, it is indicated that the HRW is excellent in terms of specific stiffness and shear tensile strength between the honeycomb wood core sandwich composite variant. By taking into account the density factor between the wood-based core sandwich composite variant, HRW sandwich composite has an optimum flexural strength and tensile shear strength while remaining at a density of $513.92 \mathrm{~kg} / \mathrm{m} 3$. Current findings add substantially to our understanding of the core sandwich composite variant based on honeycomb wood. This research has raised many questions that need further investigation. Further work needs to be done on the sandwich composite face sheet by replacing the glass fiber with natural fiber.

\section{ACKNOWLEDGEMENT}

Authors would like to thank Skim Zamalah UTeM for the financial support. The corresponding author also would like to acknowledge the sponsorship of MESTECC through grant no FRGS/1/2017/TK03/FTK-AMC/F00343 and Universiti Teknikal Malaysia Melaka for the facilities.

\section{REFERENCES}

[1] J. Susainathan, F. Eyma, E. De Luycker, A. Cantarel, and B. Castanie, Experimental investigation of impact behavior of wood-based sandwich structures, Compos. Part A Appl. Sci. Manuf., vol. 109, pp. 10-19, 2018.

[2] E. Labans, K. Kalnins, and C. Bisagni, Flexural behavior of sandwich panels with cellular wood, plywood stiffener/foam and thermoplastic composite core, J. Sandw. Struct. Mater., vol. 21, no. 2, pp. 784-805, 2019.

[3] S. Blagodatsky, J. Xu, and G. Cadisch, Carbon balance of rubber (Hevea brasiliensis) plantations: A review of uncertainties at plot, landscape and production level, Agric. Ecosyst. Environ., vol. 221, pp. 8-19, 2016.

[4] J. P. Vitale, G. Francucci, J. Xiong, and A. Stocchi, Failure mode maps of natural and synthetic fiber reinforced composite sandwich panels, Compos. Part A Appl. Sci. Manuf., vol. 94, pp. 217-225, 2017.

[5] Z. Sun, S. Shi, X. Guo, X. Hu, and H. Chen, On compressive properties of composite sandwich structures with grid reinforced honeycomb core, Compos. Part B Eng., vol. 94, pp. 245-252, 2016.

[6] A. Riccio, A. Raimondo, S. Saputo, A. Sellitto, M. Battaglia, and G. Petrone, A numerical study on the impact behaviour of natural fibres made honeycomb cores, Compos. Struct., vol. 202, pp. 909-916, 2018.

[7] N. Lakreb, S. Knapic, J. S. Machado, B. Bezzazi, and H. Pereira, Properties of multilayered sandwich panels with an agglomerated cork core for interior applications in buildings, Eur. J. Wood Wood Prod., vol. 76, no. 1, pp. 143-153, 2018.

[8] E. S. Zaini, M. D. Azaman, M. S. Jamali, and K. A. Ismail, Synthesis and characterization of natural fiber reinforced polymer composites as core for honeycomb core structure: A review, J. Sandw. Struct. Mater., vol. 22, no. 3, pp. 525-550, 2020.

[9] J. Walsh, H.-I. Kim, and J. Suhr, Low velocity impact resistance and energy absorption of environmentally friendly expanded cork core-carbon fiber sandwich composites, Compos. Part A Appl. Sci. Manuf., vol. 101, pp. 290-296, 2017.

[10] C. Caglayan, I. Gurkan, S. Gungor, and H. Cebeci, The effect of CNT-reinforced polyurethane foam cores to flexural properties of sandwich composites, Compos. Part A Appl. Sci. Manuf., vol. 115, pp. 187-195, 2018.

[11] C. Chen, Y. Li, Y. Gu, M. Li, and Z. Zhang, Improvement in skin-core adhesion of multiwalled carbon nanotubes modified carbon fiber prepreg/Nomex honeycomb sandwich composites, $J$. Reinf. Plast. Compos., vol. 36, no. 8, pp. 608-618, 2017.

[12] M. Dawood and L. Peirick III, Connection development and in-plane response of glass fiber reinforced polymer sandwich panels with reinforced cores, Can. J. Civ. Eng., vol. 40, no. 11, pp. 1117-1126, 
Mohd Yuhazri Yaakob et al., International Journal of Emerging Trends in Engineering Research, 8(1.2), 2020, 195 - 200

2013.

[13] Y. Uraki, L. Zhou, Q. Li, T. B. Bardant, and K. Koda, Honeycomb-patterned Cellulose as a Promising Tool to Investigate Wood Cell Wall Formation and Deformation, Cellul. Sci. Technol. Chem. Anal. Appl., p. 423, 2018. 